$\S=-1$

\title{
Kinetics and Thermodynamics of Adsorption Process Using A Spent-FCC Catalyst
}

\author{
Zakir Hussain ${ }^{1}$, Rakesh Kumar ${ }^{1}$, Deepa Meghavathu ${ }^{2 *}$ \\ ${ }^{I}$ Department of Chemical Engineering, Rajiv Gandhi Institute of Petroleum Technology, Jais, Amethi-229304, Uttar Pradesh, India. \\ ${ }^{2}$ Department of Chemical Engineering, Andhra University College of Engineering, Visakhapatnam-530003, Andhra Pradesh, India. \\ *Corresponding author Email: dmeghavathu.chem@auvsp.edu.in
}

\begin{abstract}
Adsorption is potentially an attractive technique for the treatment of wastewater containing dyes. In the present work, spent fluid catalytic cracking catalyst (SFCC), a petroleum refinery waste was explored as a novel adsorbent and report its adsorption capability for the first time in the literature. Batch adsorption studies were carried out to remove methylene blue (MB) dye using SFCC. The equilibrium data was modeled using pseudo-first-order, pseudo-second-order, Elovich and intraparticle diffusion models. Also, the van't Hoff equation was used to obtain the thermodynamic contributions of the process. Results show that the plot of intraparticle diffusion model (considering only film diffusion) has less $\mathrm{R}^{2}$ value $(0.887)$; it seems that the plot is nonlinear. Hence, the data points were represented by a double linear set of equations (lines) considering both pore \& film diffusion. In the first straight line, the sudden increase in slope signifies that the dye molecules were transported to the external surface of the adsorbent through film diffusion. The second straight line signifies that the dye molecules diffused through the pores. The portion which does not pass through the origin indicates that the pore diffusion is the only rate-determining step for the transport of MB onto SFCC.
\end{abstract}

Keywords: Adsorption; Petroleum refinery waste; FCC catalyst; Intra particle diffusion model; Methylene blue; Film diffusion; Pore diffusion

\section{Introduction}

Dyes can be removed from wastewater using physical, chemical, and biological means[1,2]. Many conventional or nonconventional processes, such as biological, physicochemical, filtration treatment or advanced oxidation process (AOP) were tested for dyes degradation. However, they are energy intensive, costly and generates carcinogenic byproducts. Among all these processes adsorption was found to be a most attractive technique[3].

Dyes are used frequently for many industrial applications such as dyeing of fabrics in the textile industry, as food additives in relatively minute quantities in food industries, as foam additives in the leather industry, coloring agents in the plastic industry, cosmetics, and colored paper-making in the paper industry and as coloring compounds in printing. During these applications, a lot of unused dyes are discharged as effluents. This results in water pollution and is harmful to human beings and environment[4]. Methylene blue is a heterocyclic aromatic compound and has many applications industrially, making it one of the most widely used dyes [5]. So removal of MB from the effluents requires considerable attention.

Attention towards these pollutants is not the recent one. However, increasing levels of pollutants alarm the concern towards environment regularly. As a result of serious efforts of many researchers around the world, a number of methodologies with varying degrees of success has been developed to manage water pollution. Some of them include coagulation, foam filtration, filtration, ion exchange, sedimentation, solvent extraction, adsorption, electrolysis, chemical oxidation, chemical precipitation and membrane process[5-8]. However, due to the focus on need-based activities to protect our environment, the adsorption which is widely adopt- ed technique and favored by the availability of vast natural resources as adsorbents was chosen. Also, adsorption is the most effective, commonly employed and most frequent phenomenon encountered for addressing many practical problems.

Adsorbents ranging from natural sources to artificial sources had used and have been using by many researchers and continue research to explore many new adsorbent materials day by day to lower the wastewater treatment cost[6,8].

Fluid Catalytic Cracking (FCC) catalyst is the major game changer in the downstream petroleum refinery operations. A modern FCC catalyst is in the form of fine powders with an average particle size in the range of 75 microns, with a well-defined lattice (pyramid) structure between silica and alumna atom at the center of the tetrahedron, and oxygen atoms at the four corners. It has four major components: Zeolite, Matrix, Binder, and Filler [9].

A huge quantity of spent fluid catalytic cracking catalyst (SFCC) is disposed regularly in the refineries and founds very limited applications. Moreover, as per our knowledge, there is no reported literature on SFCC as an adsorbent. Therefore, SFCC which is low/no cost adsorbent completely utilized and disposed waste from petroleum refinery was chosen as a novel adsorbent.

In the Present work, SFCC was utilized as an adsorbent for removing methylene blue from its modeled aqueous solution. Batch adsorption data was generated by varying the parameters affecting the adsorption performance such as contact time, the initial concentration of $\mathrm{MB}$, dosage of adsorbent, temperature, and $\mathrm{pH}$. Various kinetic models (pseudo-first order, pseudo-second order, Elovich \& intraparticle diffusion) along with thermodynamic contributions as per Van't Hoff equation were applied to find the nature of adsorption process. 


\section{Materials \& Methods}

\subsection{Materials}

Analytical reagents like methylene blue, $\mathrm{NaOH}, \mathrm{HCl}$ were obtained from Indica scientific, Visakhapatnam and SFCC as a gift sample was obtained from HPCL refinery, Visakhapatnam, India.

\subsection{Experimental Procedure}

A stock solution of $1000 \mathrm{ppm}$ MB concentration was prepared by dissolving $1 \mathrm{~g}$ of $\mathrm{MB}$ powder in $1 \mathrm{~L}$ double distilled water. Further, the stock solution was diluted to the required concentrations of 20 , $40,60,80,100 \mathrm{mg} \mathrm{L}^{-1}$ as per the requirement. MB Solution of desired concentration and $\mathrm{pH}$ along with the desired amount of adsorbent dosage was taken in $250 \mathrm{ml}$ conical flask and agitated at $160 \mathrm{rpm}$ in an orbital shaker

After adsorption, the supernatant was separated from the adsorbent using a centrifuge. The concentration of dye in the supernatant was determined using UV-Visible spectrophotometer (WENSAR make). The absorbance of the MB dye solution was measured at the characteristic wavelength $\left(\lambda_{\max }\right)$ of $665 \mathrm{~nm}$. The maximum limit of absorbance for UV-Visible spectrophotometer is 3 for WENSAR instrument. So the samples were diluted if the measured absorbance of the solution exceeds the value of 3 .

The calibration plot was established between the known concentrations of the MB dye solution and the corresponding measured absorbance. It was ensured that a linear relationship exists between the concentration and measured absorbance of the solution. The slope obtained from the calibration plot was used to determine the concentration of MB dye in the solution after completion of adsorption. The \%adsorption and the dye uptake were calculated from the first two equations given in Table 1 .

All the parameters affecting the adsorption performance such as contact time (5-35 min), Initial concentration (20-100 mg/l), Dosage (0.3-0.7 g), Temperature $(298-333 \mathrm{~K})$ and $\mathrm{pH}(2-9)$ were studied and the results were used to model the process.

\section{Results and Discussions}

Kinetic models: Pseudo-first order, pseudo-second order, Elovich $\&$ intraparticle diffusion models along with thermodynamic model equations are given in Table 1 were tested.

Table 1:. Model equations used

\begin{tabular}{|c|c|c|}
\hline Model & Simplified Equation & $\begin{array}{l}\text { Reference } \\
\text { number }\end{array}$ \\
\hline \% Adsorption & $\% A=\left(C_{i}-C_{o}\right) / C_{i} * 100$ & \multirow[t]{2}{*}{ [1-3] } \\
\hline Dye uptake & $\mathrm{Q}=\left(\mathrm{C}_{\mathrm{i}}-\mathrm{C}_{\mathrm{o}}\right) \mathrm{V} / \mathrm{W}$ & \\
\hline Pseudo $1^{\text {st }}$ order & $\begin{array}{c}\log \left(\mathrm{Q}_{\mathrm{eq}}-\mathrm{Q}\right)=\log \mathrm{Q}_{\mathrm{eq}}- \\
\left(\mathrm{K}_{\mathrm{I}} / 2.303\right) \mathrm{t}\end{array}$ & \multirow{6}{*}{ [3-9] } \\
\hline Pseudo $2^{\text {nd }}$ order & $\mathrm{t} / \mathrm{Q}=\left(1 / \mathrm{KII}^{*} \mathrm{Q}_{\mathrm{eq}}{ }^{2}\right)+\left(1 / \mathrm{Q}_{\mathrm{eq}}\right) \mathrm{t}$ & \\
\hline Elovich & $\mathrm{Q}=(1 / \beta) \ln (\alpha \beta)+(1 / \beta) \operatorname{lnt}$ & \\
\hline Intra particle diffusion & $\mathrm{Q}=\mathrm{K}_{\mathrm{diff}} * \mathrm{t}^{0.5}+\mathrm{C}$ & \\
\hline Van't Hoff & $\ln K_{a}=(-\Delta H / R T)+\Delta S^{\#} / R T$ & \\
\hline Gibbs Free energy & $\Delta \mathrm{G}=\Delta \mathrm{H}+\mathrm{T} \Delta \mathrm{S}$ & \\
\hline
\end{tabular}

\section{Where,}

$\mathrm{C}_{\mathrm{i}}$ and $\mathrm{C}_{\mathrm{o}}$ are the initial and final concentration of dye respectively.

$\mathrm{Q}_{\mathrm{eq}}$ is the equilibrium dye uptake.

$\mathrm{V}$ is the volume of dye solution taken.

$\mathrm{w}$ is the weight of adsorbent used.

$t$ is the adsorption (contact) time.

$\mathrm{T}$ is the temperature of the adsorption.

$\mathrm{K}_{\mathrm{I}}$ and $\mathrm{K}_{\mathrm{II}}$ are the rate constants

$\alpha$ is a constant related to chemisorption rate.

$\beta$ is a constant which depicts the extent of surface coverage.

$\mathrm{K}_{\text {diff }}$ is the diffusion coefficient.
$\mathrm{K}_{\mathrm{a}}$ is the equilibrium or distribution constant.

$\Delta \mathrm{H}, \Delta \mathrm{S}$, and $\Delta \mathrm{G}$ are the change in enthalpy, entropy, and Gibbs free energy respectively.

\subsection{Kinetic Models}

\subsubsection{Pseudo-First-Order Model}

Pseudo-first-order kinetic model was tested in order to obtain the first order rate constant $\left(\mathrm{K}_{\mathrm{I}}\right)$. The linear plot as shown in Fig. 1 is drawn between $\log \left(\mathrm{Q}_{\mathrm{eq}}-\mathrm{Q}\right)$ versus time $(\mathrm{t})$. Basic hypothesis followed here is that when $\mathrm{Q}_{\mathrm{eq}}$ obtained from the intercept of this plot is not equal to the $\mathrm{Q}_{\mathrm{eq}}$ observed then the reaction is not likely to be followed by pseudo-first-order kinetics, even though the plot has high correlation coefficient. It was observed that the calculated value of $\mathrm{Q}_{\mathrm{eq}}$ was $5.0408 \mathrm{mg} \mathrm{g}^{-1}$ is not equal to the observed $\mathrm{Q}_{\mathrm{eq}}$ $=3.205 \mathrm{mg} \mathrm{g}^{-1}$, suggesting that the pseudo-first-order-model is not valid in the present case.

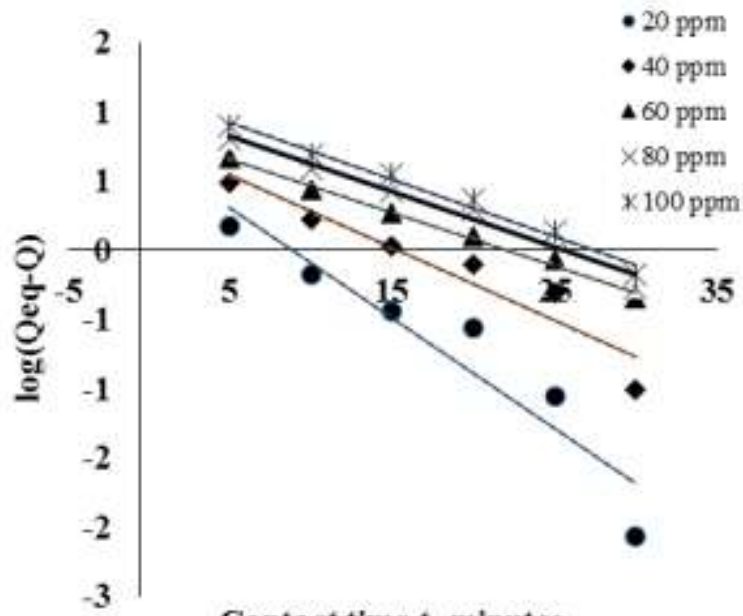

Contact time t, minutes

Fig.1: Pseudo $1^{\text {st }}$ order model plot

\subsubsection{Pseudo-Second Order Model}

Pseudo-second order model was used to explain the sorption kinetics and is based on the assumption that the adsorption follows second order chemisorption. A plot between $t / Q$ and $t$ was drawn as shown in Fig.2, the regression values were found to be high and the error between the model dye uptake $\left(\mathrm{Q}_{\mathrm{eq}}=3.378\right)$ and experimental dye uptake $\left(Q_{e q}=3.205\right)$ was also minimum. Thus it was observed that the pseudo-second-order kinetic model is the best fit for the present data. The rate constant values obtained in case of pseudo-first-order and pseudo-second-order kinetic models are given in Table 2.

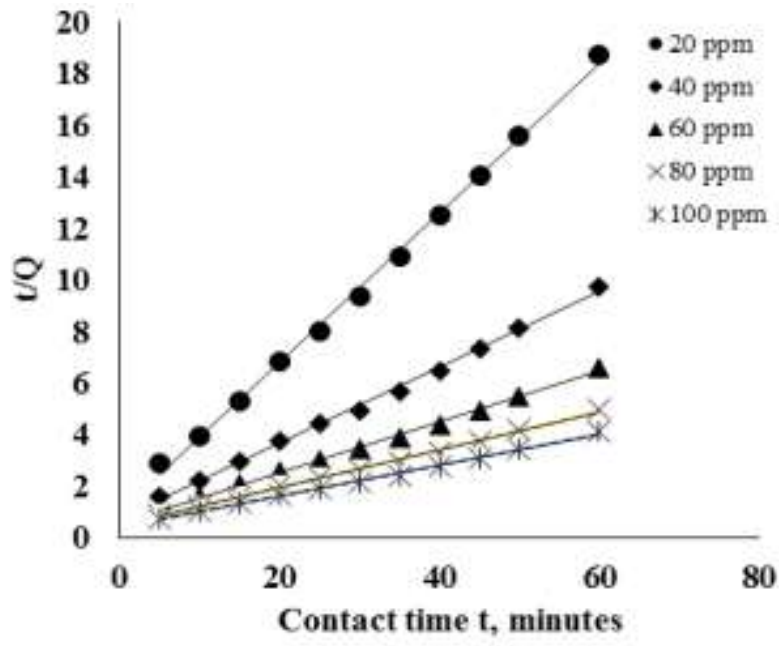

Fig.2: Pseudo $2^{\text {nd }}$ order model plot 


\subsubsection{Elovich Model}

A Plot between $\mathrm{Q}$ and $\ln [\mathrm{t}]$ was drawn and is shown in Fig.3. The slope of this plot was inverted to find the value of chemisorption rate $\beta$ and was found to be $0.065 \mathrm{~g} / \mathrm{mg}$. Using the values of $\beta$ and intercept of Elovich plot the value of ' $\alpha$ ' was found to be 1.869 $\mathrm{mg} / \mathrm{g}$ min. These values once again confirm that the adsorption process is chemisorption due to the strong binding forces.

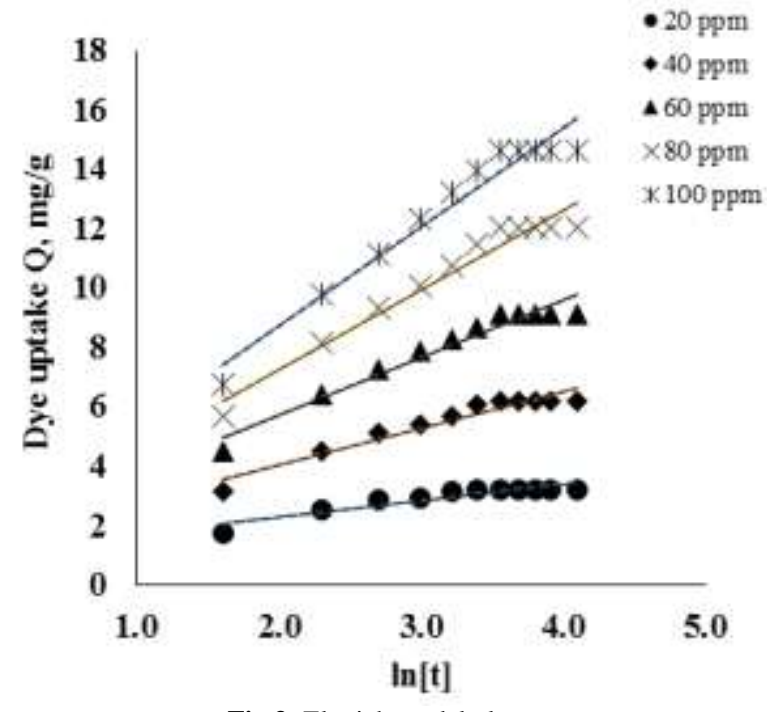

Fig.3: Elovich model plot

\subsubsection{Intraparticle Diffusion Model}

Ions are most probably transported from the bulk of the solution on to the solid phase by intraparticle diffusion, which is often the rate-limiting step in many adsorption processes. A single plot of $\mathrm{Q}$ $\mathrm{Vs} \mathrm{t}^{\wedge} 0.5$ gives the mechanism for transport of molecules.

Figure 4 indicates that the plot has low $\mathrm{R}^{2}$ values $(0.887)$, it seems that the plots are nonlinear for all the concentrations. Hence, the data points were represented by a double linear set of equations as shown in Fig. 5.

In the first straight line, the sudden increase in slope signifies that the dye molecules are transported to the external surface of the adsorbent through film diffusion.

The second straight line signifies that the dye molecules were diffused through the pores.

The portion which does not pass through the origin indicates that the pore diffusion is the only rate-determining step for the transport of MB onto SFCC.

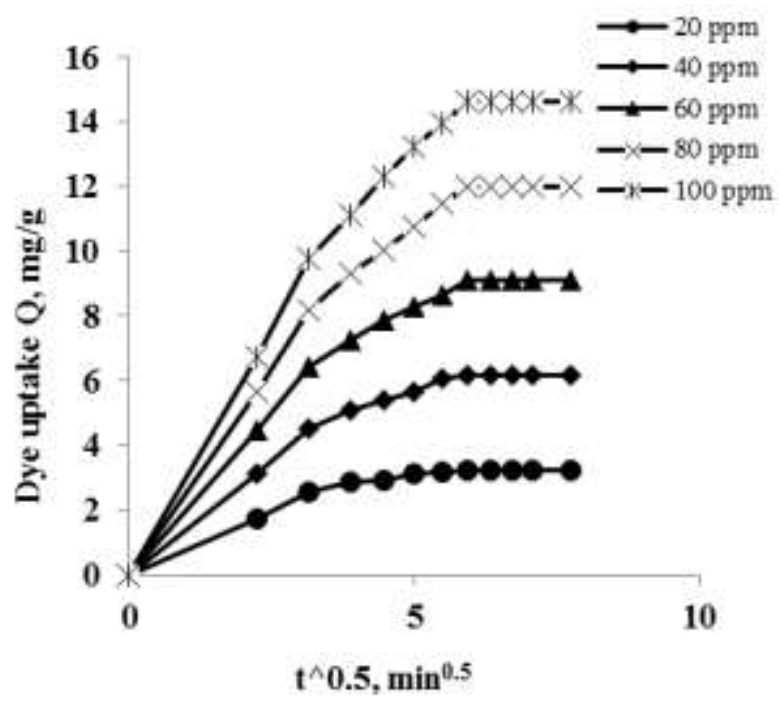

Fig.4: Intraparticle diffusion model plot considering only film diffusion

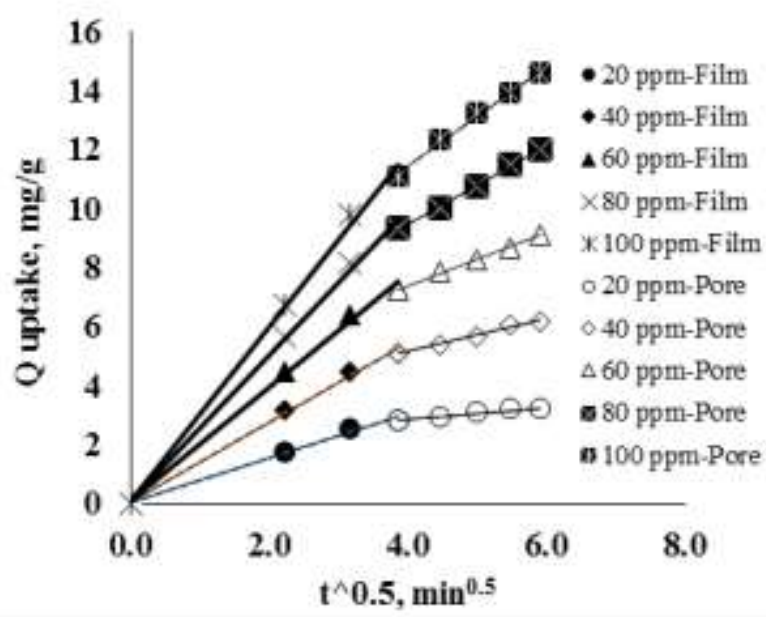

Fig.5: Intraparticle diffusion model plot considering both film and pore diffusions

Table 2:. Kinetics parameters

\begin{tabular}{|c|c|c|c|}
\hline \multicolumn{2}{|c|}{ Pseudo $1^{\text {st }}$ order } & \multicolumn{2}{|c|}{ Elovich } \\
\hline $\mathrm{Q}_{\mathrm{eq}}\left[\mathrm{mg} \mathrm{g}^{-1}\right]$ & 5.040 & A & 1.869 \\
\hline $\mathrm{K}_{\mathrm{I}}\left[\mathrm{min}^{-1}\right]$ & 0.183 & $\beta$ & 0.065 \\
\hline $\mathrm{R}^{2}$ & 0.8927 & $\mathrm{R}^{2}$ & 0.950 \\
\hline \multicolumn{2}{|c|}{ Pseudo $2^{\text {nd }}$ order } & \multicolumn{2}{|c|}{ Intra particle diffusion } \\
\hline $\mathrm{Q}_{\mathrm{eq}}\left[\mathrm{mg} \mathrm{g}^{-1}\right]$ & 3.378 & $\begin{array}{c}\mathrm{K}_{\text {diff }}\left[\mathrm{mg} \mathrm{g}^{-1}\right. \\
\left.\mathrm{sec}^{-0.5}\right]\end{array}$ & 0.195 \\
\hline $\mathrm{K}_{\mathrm{II}}[\mathrm{L} / \mathrm{mg}$-min] & 0.065 & $\mathrm{C}\left[\mathrm{mg} \mathrm{g}^{-1}\right]$ & 2.090 \\
\hline $\mathrm{R}^{2}$ & 0.999 & $\mathrm{R}^{2}$ & 0.938 \\
\hline
\end{tabular}

\subsection{Thermodynamic Studies}

The equation of van't Hoff clearly shows that the thermodynamics of adsorption process is composed mainly of two contributions (enthalpy change and entropy change). A plot of $\ln _{\mathrm{a}} \mathrm{Vs} 1 / \mathrm{T}$ as shown in Fig. 6 gives the positive $\Delta \mathrm{H}$ values ranging from 41.247 to $56 \mathrm{KJ} / \mathrm{mol}$ and $\Delta \mathrm{S}$ values from 0.211 to $0.154 \mathrm{~J} / \mathrm{mol} \mathrm{K}$. This indicates that the high temperatures are favored to drive this endothermic process.

The last equation given in Table 1 was used to calculate the change in Gibbs free energy and the obtained values are presented in Table 3. The obtained negative $\Delta \mathrm{G}$ values for all the temperature \& concentration ranges signifies that the adsorption process is spontaneous in the forward direction.

Also, the positive change in $\Delta \mathrm{S}$ values indicates the degree of irregularity in the process and satisfies the second law of thermodynamics. Table 3 represents the estimated values of all the three thermodynamic parameters.

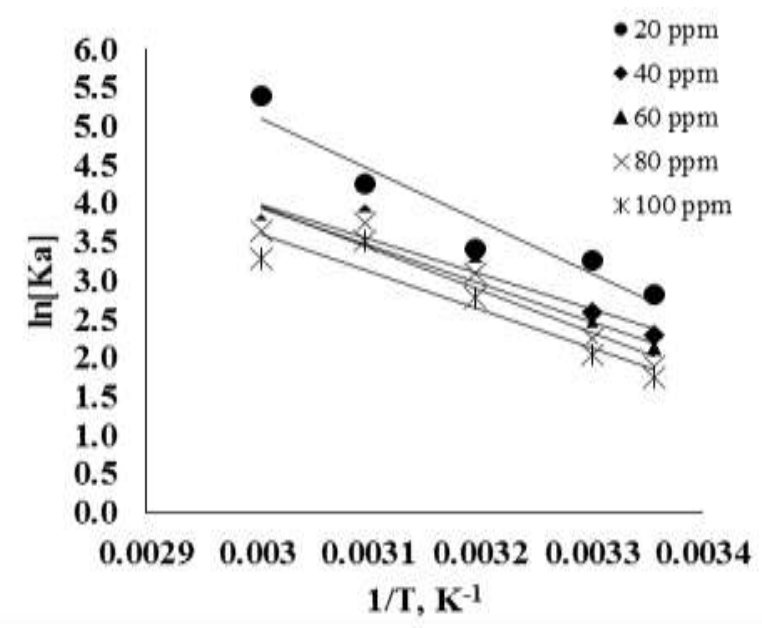

Fig.6: Van’t Hoff plot 
Table-3: Thermodynamic parameters

\begin{tabular}{|c|c|c|c|c|}
\hline $\mathbf{T}, \mathbf{K}$ & $\mathrm{C}_{\mathrm{i}, \mathrm{ppm}}$ & $\Delta \mathbf{H}, \mathbf{K J} / \mathrm{mol}$ & $\Delta \mathrm{S}, \mathrm{KJ} / \mathrm{mol}-\mathrm{K}$ & $\Delta \mathrm{G}, \mathrm{KJ} / \mathrm{mol}$ \\
\hline 298 & \multirow{5}{*}{20} & \multirow{5}{*}{56} & \multirow{5}{*}{0.211} & -6.715816 \\
\hline 303 & & & & -7.770198 \\
\hline 313 & & & & -9.878961 \\
\hline 323 & & & & -11.98772 \\
\hline 333 & & & & -14.09649 \\
\hline 298 & \multirow{5}{*}{40} & \multirow{5}{*}{37.541} & \multirow{5}{*}{0.146} & -5.905667 \\
\hline 303 & & & & -6.634639 \\
\hline 313 & & & & -8.092582 \\
\hline 323 & & & & -9.550525 \\
\hline 333 & & & & -11.00847 \\
\hline 298 & \multirow{5}{*}{60} & \multirow{5}{*}{41.479} & \multirow{5}{*}{0.157} & -5.39133 \\
\hline 303 & & & & -6.177751 \\
\hline 313 & & & & -7.750593 \\
\hline 323 & & & & -9.323436 \\
\hline 333 & & & & -10.89628 \\
\hline 298 & \multirow{5}{*}{80} & \multirow{5}{*}{45.439} & \multirow{5}{*}{0.169} & -5.007339 \\
\hline 303 & & & & -5.853746 \\
\hline 313 & & & & -7.54656 \\
\hline 323 & & & & -9.239373 \\
\hline 333 & & & & -10.93219 \\
\hline 298 & \multirow{5}{*}{100} & \multirow{5}{*}{41.247} & \multirow{5}{*}{0.154} & -4.577755 \\
\hline 303 & & & & -5.346634 \\
\hline 313 & & & & -6.884391 \\
\hline 323 & & & & -8.422149 \\
\hline 333 & & & & -9.959906 \\
\hline
\end{tabular}

\section{Conclusion}

1. The present work had identified a new source of the adsorbent for the removal of dyes.

2. The adsorption of methylene blue on spent FCC catalyst is well correlated with the pseudo-second-order kinetic model.

3. Intraparticle diffusion model shows that the adsorption process is the result of both film and pore diffusion.

4. Free energy change indicates the degree of the spontaneity of the adsorption process and the negative value of $-6.715 \mathrm{KJ} / \mathrm{mol}$ reflects more energetically favorable adsorption.

5. Enthalpy change $(\Delta \mathrm{H})$ value of 56 (i.e. positive), means the adsorption is endothermic, an increase in temperature (T) results in an increase in equilibrium constant $\mathrm{K}_{\mathrm{a}}$. The positive entropy change shows the feasibility of the process.

\section{Acknowledgment}

We would like to acknowledge the receipt of funding in the form of fellowship (No. 312206202020) provided by Government of India through the World Bank-funded project, technical education quality improvement programme (TEQIP Phase II). We would like to thank Professor Pulipati King, Professor R. Padmasree, and Professor Velluri Sridevi of Andhra University for their resourceful guidance and facilities.

\section{References}

[1] Bandary B, Hussain Z \& King P (2016), Experimental study on non sporulating Escherichia Coli bacteria in removing methylene blue. International Journal of Pharma and Bio Sciences 7, B629-B637.

[2] Bandary B, Hussain Z \& Kumar R (2016), Effect of carbon and nitrogen sources on Escherichia coli bacteria in removing dyes. Materials Today: Proceedings 3, 4023-4028. doi:10.1016/j.matpr.2016.11.067.

[3] Rafatullah M, Sulaiman O, Hashim R, Ahmad A (2010), Adsorption of methylene blue on low-cost adsorbents: A review. Journal of Hazardous Materials 177, 70-80. doi:10.1016/j.jhazmat.2009.12.047.
[4] Weng CH \& Pan YF, (2007), Adsorption of a cationic dye (methylene blue) onto spent activated clay. Journal of Hazardous Materials 144, 355-362. doi:10.1016/j.jhazmat.2006.09.097.

[5] Fatima M, Farooq R, Lindström RW, Saeed M (2017), A review on biocatalytic decomposition of azo dyes and electrons recovery. Journal of Molecular Liquids 246, 275-281. doi:10.1016/j.molliq.2017.09.063.

[6] Aluigi A, Rombaldoni F, Tonetti C, Jannoke L (2014), Study of Methylene Blue adsorption on keratin nanofibrous membranes. Journal of Hazardous Materials 268, 156-165. doi:10.1016/j.jhazmat.2014.01.012.

[7] Kumar A, Singha S, Sengupta B, Dasgupta D, Datta S, Mandal T (2016), Intensive insight into the enhanced utilization of rice husk ash: Abatement of rice mill wastewater and recovery of silica as a value added product. Ecological Engineering 91, 270-281. doi:10.1016/j.ecoleng.2016.02.034.

[8] Ho YS, Chiu WT \& Wang CC (2005), Regression analysis for the sorption isotherms of basic dyes on sugarcane dust, Bioresource Technology 96, (2005) 1285-1291. doi:10.1016/j.biortech.2004.10.021.

[9] Cahn RW \& Haasen P (2014), Fluid catalytic cracking handbook, Second edi, Gulf Professional Publishing, Houston, TX, (2014). doi:10.1016/B978-0-444-53770-6.05002-4 